\title{
Halloysite nanotubes-based nanocomposites for the hydrophobization of hydraulic mortar
}

\author{
Maria Rita Caruso, Bartolomeo Megna, Lorenzo Lisuzzo $₫$, Giuseppe Cavallaro, Stefana Milioto, \\ Giuseppe Lazzara
}

Received: 12 January 2021/Revised: 1 June 2021 / Accepted: 7 June 2021

(C) The Author(s) 2021

\begin{abstract}
The treatment of stone surfaces for their protection from ageing caused by natural and anthropogenic effects is an open issue in materials development for Cultural Heritage. We thought interesting to verify the suitability of a modified cellulose biofilm filled with halloysite nanotubes as wax compatibilizers to design a protecting layer. A hydraulic mortar was selected as a stone prototype. To improve the physicochemical properties of the covering layer, wax microparticles have been incorporated to control transport, consolidation and wettability features. In
\end{abstract}

particular, different application protocols have been studied, namely brushing and spraying, to assess whether the proposed procedures can be scaled up. Colorimetric analysis has been carried out to evidence the applicability in terms of color alteration after the treatment. Water adhesion was investigated by measuring the contact angle values as a function of time to obtain information on spreading and adsorption phenomena. These physico-chemical properties have been correlated to the microstructure evidenced by both electron and optical microscopies.

Supplementary Information The online version contains supplementary material available at https://doi.org/10.1007/s11998021-00522-9.

M. R. Caruso, L. Lisuzzo ( $₫)$, G. Cavallaro,

S. Milioto, G. Lazzara

Dipartimento di Fisica e Chimica, Università degli Studi di

Palermo, Viale delle Scienze, pad. 17, 90128 Palermo, Italy

e-mail: lorenzo.lisuzzo@unipa.it

M. R. Caruso, B. Megna, G. Cavallaro,

S. Milioto, G. Lazzara

Consorzio Interuniversitario Nazionale per la Scienza e

Tecnologia dei Materiali, INSTM, Via G. Giusti, 9, 50121

Firenze, Italy

B. Megna

Dipartimento di Ingegneria, Università degli Studi di

Palermo, Viale delle Scienze, pad. 6, 90128 Palermo, Italy 


\section{Graphic abstract}

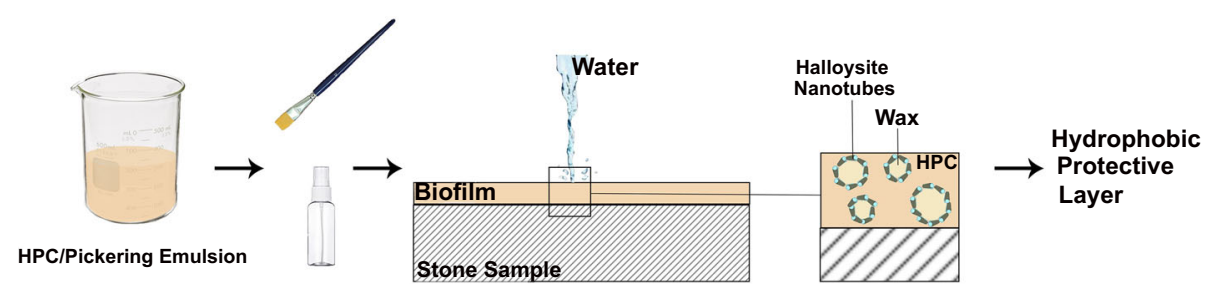

Keywords Halloysite nanotubes, Stone, Cultural heritage, Biopolymer, Nanocomposites

\section{Introduction}

Preservation of stone artworks from ageing is one open issue in material science. ${ }^{1}$ An ideal material should be easy to apply as a thin film on the stone surface without altering its aspect just after treatment and ageing as well. Moreover, it should be functional in protecting the stone surface from ageing caused by weathering effects, which can be considered more critical nowadays due to air pollution. ${ }^{2,3}$ Besides the chemical attack, one should also consider the growth of biological species on the surface. ${ }^{4}$ All these factors are enhanced if water is retained by the surface due to spreading/adsorption phenomena, which are typically present as a consequence of the hydrophilic nature of the natural stones and their porosity. The latter is actually a fundamental feature to ensure the stones breathability that is important to keep the material dry and, therefore, it should be kept even after a surface cover layer is applied for protection purposes. ${ }^{5,6}$ Last but not least, a coating layer should be durable but also reversible. Late in the 1980s, many incompatible and ineffective protective coatings were used and they, by remaining on the surface subjected to continuous ageing for a long time, regrettably generated an irreversible damage of the stone.

Protective layers could be: (1) superhydrophobic coatings to guarantee low water adhesion, so that pollutants and microorganisms are washed away and (2) photocatalytic coatings that favor the light induced degradation of organic deposit on the surface and therefore they can generate self-cleaning properties. $^{8-10}$ During the last decade, nanoparticles were proposed to target the required performance of such coatings. ${ }^{11-16}$ Silica-based resins are commercially available and they have been deeply investigated as the stone/resin interactions are crucial to define the surface properties and the efficacy of the coating layer. ${ }^{17,18}$

More recently, biopolymers are considered perspective candidates as they have been defined "intrinsically reversible" because they are expected to vanish from the stone surface once their action has ceased or to produce nonaggressive residues, and they do not create any issues in subsequent conservation treatments. ${ }^{19-22}$ Actually, biopolymers are widely used in restoration protocols as thickening agents for cleaning formulations and, to some extent, they have been introduced as coatings against sulphation or to enhance water repellency. ${ }^{23-29}$ Their combination with nanoparticles is a promising strategy to further improve the physicochemical properties. ${ }^{30-33}$ It should be noted that although it appears a perspective direction, the evaluation of biopolymeric films effectiveness in real cases is still at a preliminary stage and it needs deeper investigations. In particular, proper additives must be found in order to tune the interfacial properties.

Wax, mainly beeswax, is another biomaterial that has been used to protect marble statues. Being liquid at high temperature (typically $50-60^{\circ} \mathrm{C}$ ) and soluble only in organic solvents, the main difficulty in the employ of wax is related to its application. ${ }^{34}$ In this case, these features make the application of covering layers not sustainable and sometimes detrimental for the artifacts. $^{35}$

With this in mind we thought interesting to investigate a biopolymeric matrix (hydroxypropylcellulose, HPC) well known in the restoration protocols as reversible consolidant, glue and for its film forming ability with microwax particles homogeneously dispersed. $^{36-38}$ To achieve this target, a wax in water Pickering emulsion was prepared by using halloysite nanotubes as stabilizing agents. The use of halloysite natural nanotubular clay as stabilizers in Pickering emulsion is well documented. ${ }^{39-42}$ Moreover, due to their peculiar morphology, ${ }^{43-46}$ biocompatibility ${ }^{47,48}$ and miscibility with biopolymer in solid films,${ }^{49-51}$ they are considered promising materials in different applications for consolidation and protection of Cultural Heritage, ${ }^{52,53}$ as well as in other industrial fields such as food packaging and pharmaceutical formulations. ${ }^{54-59}$ As stone substrate, we prepared a hydraulic mortar with artificial ageing.

\section{Experimental section}

\section{Materials}

Halloysite nanotubes, HNTs $\left(\mathrm{Al}_{2} \mathrm{Si}_{2} \mathrm{O}_{5}(\mathrm{OH})_{4} \cdot 2 \mathrm{H}_{2} \mathrm{O}\right)$, were a gift from I-Minerals Inc., and they possess ca. $9.5 \%$ of flat kaolinite particles. Hydroxypropyl cellu- 
lose (HPC) with $\mathrm{Mw}=80 \mathrm{~kg} \mathrm{~mol}^{-1}$ and microcrystalline wax (mp. $45-60^{\circ} \mathrm{C}$ ) were from Sigma-Aldrich.

\section{Methods}

Fourier transform infrared (FTIR) measurements were taken at room temperature through a Frontier FTIR spectrometer (PerkinElmer). The spectral resolution was $2 \mathrm{~cm}^{-1}$ and for each analysis 64 scans in the range between 4000 and $450 \mathrm{~cm}^{-1}$ were carried out. Scanning electron microscopy was conducted by using an ESEM FEI QUANTA 200F microscope coupled with an energy-dispersive X-ray (EDX) spectrometer that provides the elemental analysis. In order to avoid electron charging, the surface of the sample was coated with gold in argon by means of an Edwards Sputter Coater S150A before each measurement. The experiments were conducted in high vacuum mode $\left(<6 \times 10^{-4} \mathrm{~Pa}\right)$ for simultaneous secondary electron with a beam energy of $10 \mathrm{kV}$ and a working distance of $10 \mathrm{~mm}$. The polished cross sections were prepared by embedding the mortar samples in a transparent epoxy resin, i.e., epofix by Struers. After resin curing, the surface to be observed was polished by means of silicon carbide abrasive papers from 320 to 4000 grit. The polished cross sections were observed by means of a Leica MS5 stereoscopic microscope, and the images have been acquired through a Leica MD170HD camera using Leica Application Suite v4.3. Moreover, a polished cross section was observed in the previously described SEM using low vacuum mode, 0.4 mbar water vapor pressure, in order to avoid gilding.

Color parameters of films were measured using a colorimeter (NH300 Colorimeter, 3NH Shanghai Co., Ltd.) and CQCS3 Software for data acquisition. $L^{*}$ (lightness), $\mathrm{a}^{*}$ (red-green) and $b^{*}$ (yellow-blue) parameters were measured and compared with an untreated stone. To this purpose, the total color differences $(\Delta E)$ were calculated. ${ }^{60}$ UV-VIS spectra of HPC film and wax/HNTs/HPC nanocomposites were recorded by a Specord S600 (Analytik, Jena, Germany) in the range between 200 and $800 \mathrm{~nm}$ and they were analyzed in terms of transmittance $(\mathrm{T} \%)$.

Water contact angle was measured by means of an optical contact angle apparatus (OCA 20, Data Physics Instruments) equipped with a video measuring system having a high-resolution CCD camera and a highperformance digitizing adapter. SCA 20 software (Data Physics Instruments) was used for data acquisition. The contact angle $(\vartheta)$ of water in air was measured by the sessile drop method by gently placing a droplet of $12.0 \pm$ $0.5 \mu \mathrm{L}$ onto the surface. Images were collected 25 times per second, starting from the deposition of the drop. A minimum of 3 droplets were examined for each surface.

\section{Stone sample materials}

Stone samples were used to assess the effect of wax microparticles on the hydroxypropyl cellulose-based

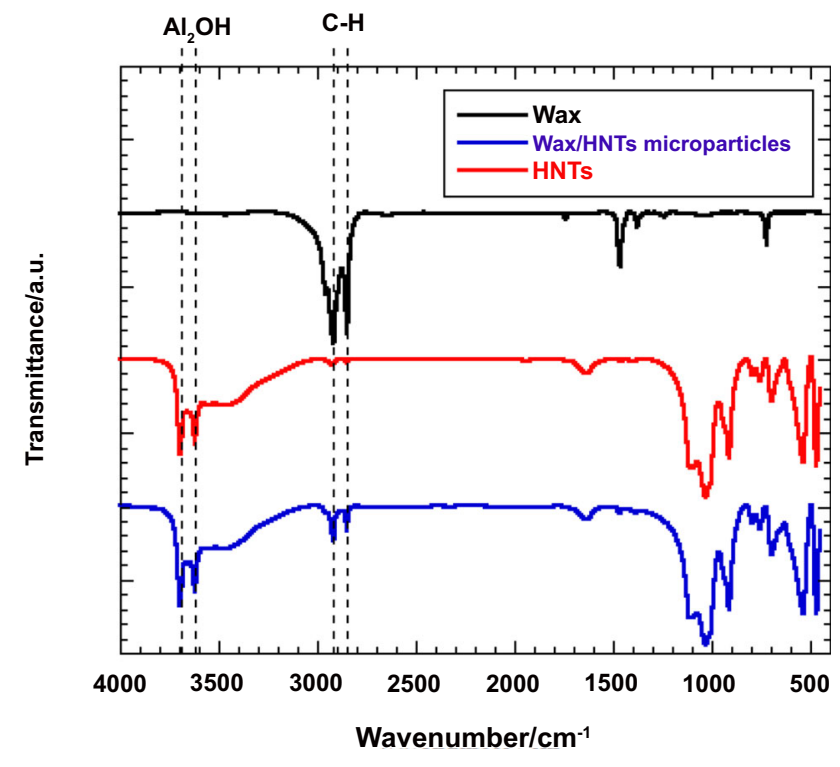

Fig. 1: Fourier transform infrared spectra for pure wax, halloysite and wax/HNTs microparticles.

film. The sample preparation involved hydraulic lime and silica river sand, as aggregate, mixed with water. The mortar was placed in silicone molds, shaped as prisms with a rectangular base, to form the samples $\left(5 \times 10 \times 2.5 \mathrm{~cm}^{3}\right)$. After 5 days inside the mold (UR $65 \%$ ), the samples were removed and left to mature for 60 days at a temperature of $20^{\circ} \mathrm{C}$ and relative humidity of $95 \%$.

\section{Application on stone surface}

We employed both hydroxypropyl cellulose aqueous solution (3 wt \%) and wax/HNT Pickering emulsion with HPC. In this case, the composition was $3 \mathrm{wt} \%$ HPC, $0.25 \mathrm{wt} \%$ wax and $1.5 \mathrm{wt} \%$ halloysite nanotubes. This formulation allowed us to obtain a stable system for the application on the solid substrate. Each dispersion was prepared according to the following protocol. Wax and halloysite nanotubes were added to hot water $\left(90^{\circ} \mathrm{C}\right)$ under magnetic stirring for $1 \mathrm{~h}$. Afterwards, the system was cooled down to room temperature whilst stirring to allow the wax to solidify to form the microparticles. The obtained emulsion was stable for a day at least. Hydroxypropyl cellulose was added to the emulsion and magnetically stirred for at least $24 \mathrm{~h}$ before application on the stone substrate. The coating protocol was performed by using two different methods: a brush and a spray application. For each procedure, the coating was applied twice and the second treatment was performed after $24 \mathrm{~h}$ from the first treatment. The treated stone samples were kept at ambient conditions (temperature of $25^{\circ} \mathrm{C}$ and a relative 

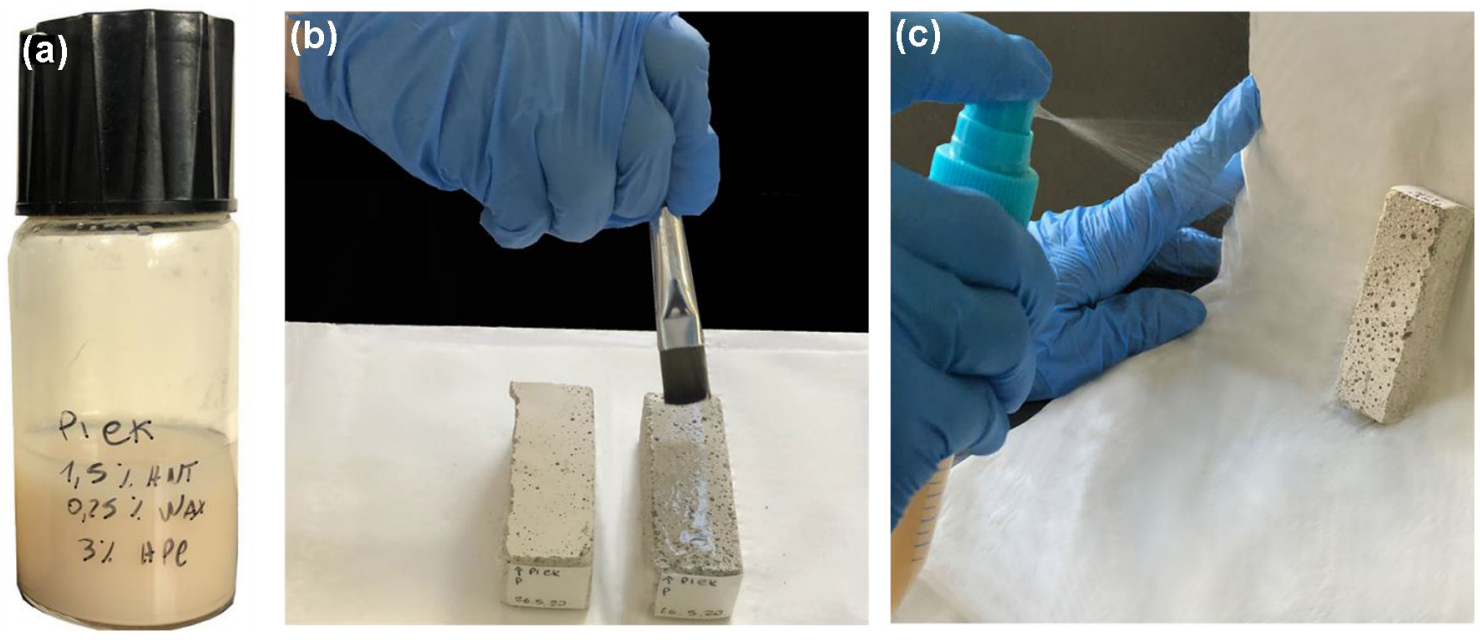

Fig. 2: Wax/halloysite Pickering emulsion system in HPC after $48 \mathrm{~h}$ (a) Photographs of the application methods conducted by brush (b) and spray (c).
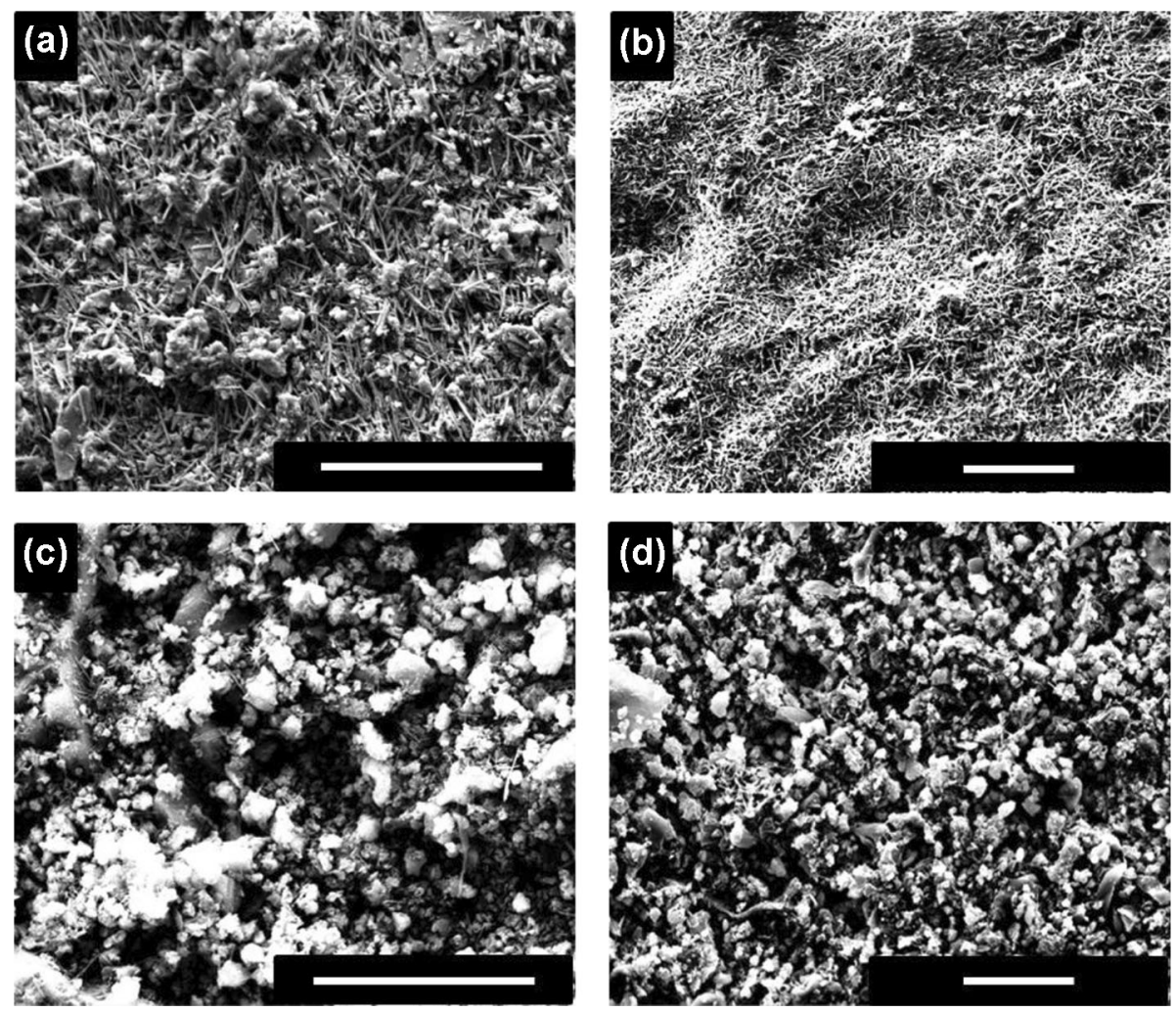

Fig. 3: SEM images of the stone surface treated with HPC aqueous solution and wax/HNT in HPC by spray (a, c) and brush (b, d), respectively. Scale bars are $20 \mu \mathrm{m}$.

humidity of $45 \%$ ) for at least 48 h before any characterization test.

\section{Results and discussion}

Preparation and morphological properties of the protective coating

The first step of this work was the design of the wax/ HNTs Pickering emulsions, which converted into solid 
microparticles upon cooling down. This system was characterized by FTIR spectroscopy, as reported in Fig. 1.

As it can be observed, the main peaks of halloysite nanotubes can be clearly distinguished in the hybrid microparticles, and namely the two $\mathrm{OH}$-stretching bands at 3695 and $3620 \mathrm{~cm}^{-1}$ related to the vibrations of the $\mathrm{Al}_{2} \mathrm{OH}$ groups inside the lumen. ${ }^{50}$ Similarly, the large absorption bands between 3000 and $2800 \mathrm{~cm}^{-1}$ corresponding to the $\mathrm{C}-\mathrm{H}$ stretching for the $-\mathrm{CH}_{3}$ and $-\mathrm{CH}_{2}$ groups of paraffin are still present. ${ }^{61}$ Both signals do not show relevant changes in terms of shifting or splitting in the wax/HNTs microparticles. The polymeric structure of wax is not affected by the addition of the nanoclays, which are physically adsorbed at the interface of the microparticles and entrapped by the solid core.

The preparation of the nanocomposite formulation resulted in a stable and well-dispersed system composed of halloysite/wax microparticles in HPC. The stability could be observed for a long time frame and it did not change even after 48 h, as reported in Fig. 2a.

Both the methods employed for the treatment of the mortar stone, namely brushing and spraying the surface (Figs. 2b and 2c), allowed to estimate the effect of the application procedures on the coating layers. In principle, the spray method guarantees a homogeneous distribution of the solution with a minimum quantity of product compared to the brush method where it is difficult to control the amount of product applied to the surface.

Once the protective coating was applied on the surface of the hydraulic mortar, SEM analysis was conducted. Regardless of the specific application protocol, only the cellulosic material can be clearly observed on the mortar surface in its fibrous morphology when the samples are treated just with HPC aqueous solution (Figs. 3a and $3 b$ ). On the contrary, it is noteworthy that the wax/nanotubes microparticles can be recognized in their typical spherical shape when the complete formulation is employed as a protective layer (Figs. 3c and 3d). In particular, their diameter range was estimated to be $4-7 \mu \mathrm{m}$ by analyzing the micrographs reported in Fig. 3. In light of these observations, the preparation procedure of the multicomponent system, which has the melting/solidification of wax as a crucial step, and both the application protocols (i.e., brush and spray) allow to maintain the morphological properties of the microparticles even upon drying and water evaporations. The presence of HPC and the interaction with the stone substrate do not alter the particle stability and their proper features, in agreement with literature. ${ }^{62}$

Afterwards, in order to estimate the efficiency of the two methods, the polished cross sections of the treated samples were observed. Optical microscopy allowed to easily note that the spray application leads to a more uniform protective coating, with a width in the order of tens of microns, and the surface of the stone is homogeneously covered. Contrarily to it, the brush procedure results in a not uniform coating and some stone grains are still exposed to the external surface and to the air (Fig. 4).

Therefore, after treating the stone with the wax/ HNT in HPC protective biofilm by the spray method, it is possible to clearly identify the presence of the outer layer, which is perfectly adherent to the substrate, by both optical and scanning electron microscopies (Fig. 5a,b). In this case, the thickness of the coating layer was estimated to be ca. $10 \mu \mathrm{m}$. Aimed at studying the chemical nature of this external coating, an EDX elemental analysis was performed and it revealed the presence of high amounts of aluminum thus undoubtedly indicating the presence of halloysite nanotubes, as a unique component based on $\mathrm{Al}$ species present in the formulation (Figure 5c). These findings clearly indicate the suitability of the reported protocol for the coating of stone surfaces.
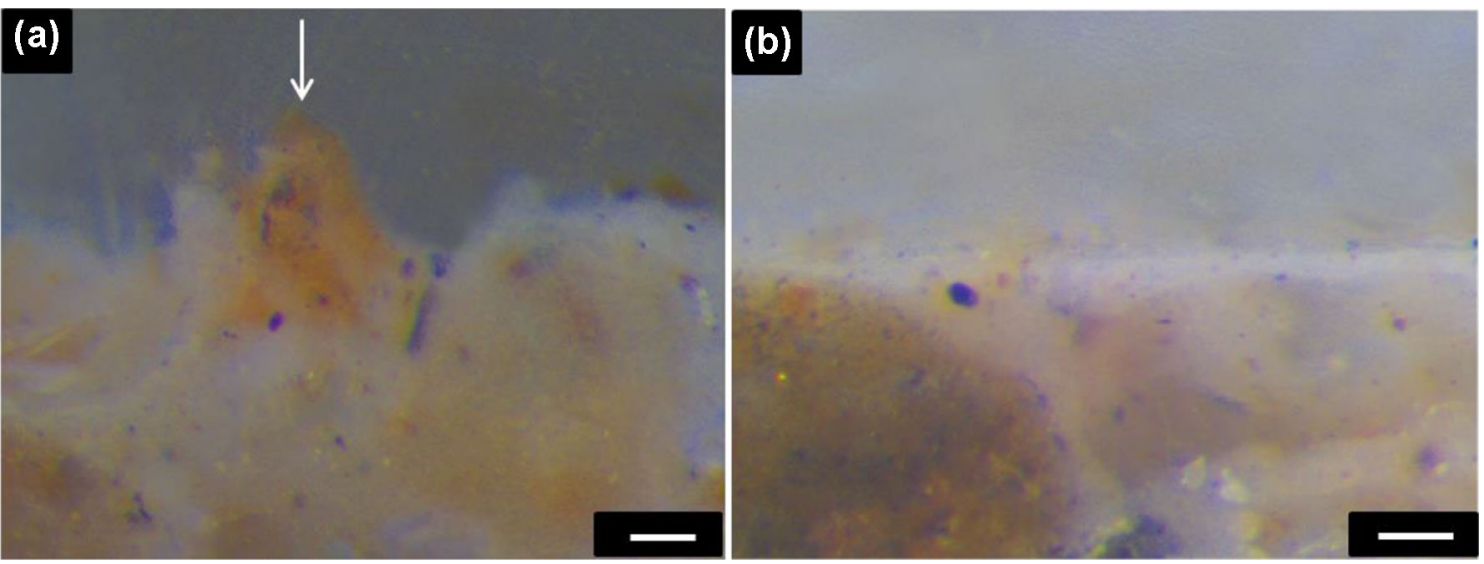

Fig. 4: Optical images of polished cross sections after treating the stone with the protective formulation by brush (a) and spray (b) methods. The white arrow in (a) indicates a stone grain. Scale bars are $100 \mu \mathrm{m}$. 


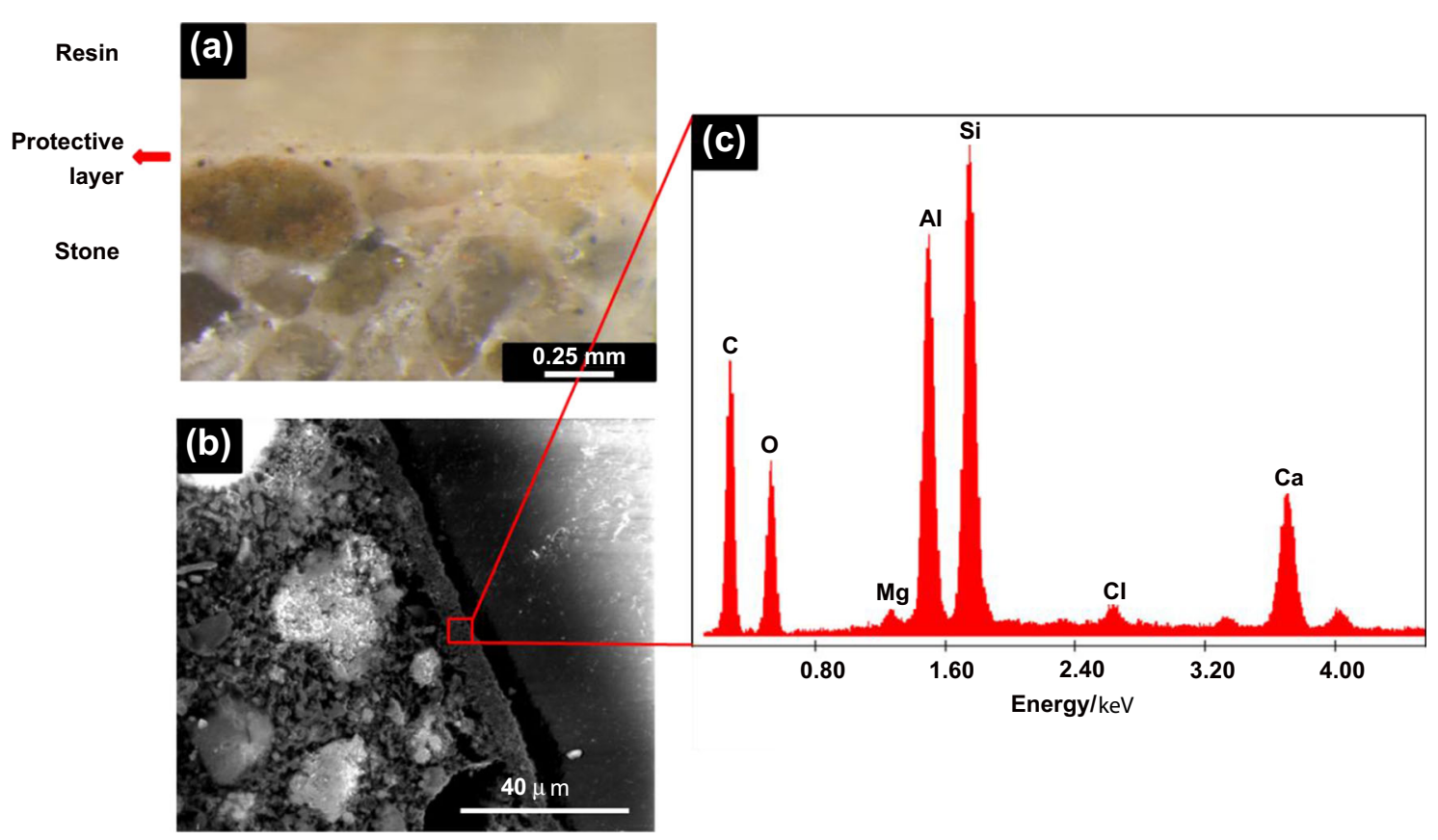

Fig. 5: Optical image (a), SEM micrograph (b) and EDX spectrum (c) of the stone sample cross section after treatment with wax/HNT in HPC formulation.

Table 1: Color Parameters ${ }^{a}$

\begin{tabular}{llrr} 
& $L^{*}$ & $a^{*}$ & $b^{*}$ \\
\hline Untreated sample & 83.844 & 0.716 & 5.396 \\
HPC & 83.844 & 0.768 & 6.848 \\
HPC/microwax particles (spray) & 80.997 & 0.787 & 7.184 \\
HPC/microwax particles (brush) & 79.523 & 1.271 & 9.548 \\
\hline
\end{tabular}

${ }^{\mathrm{a}}$ Control: White Paper standard, $L^{*}=97.166, a^{*}=-0.337, b^{*}=0.224$

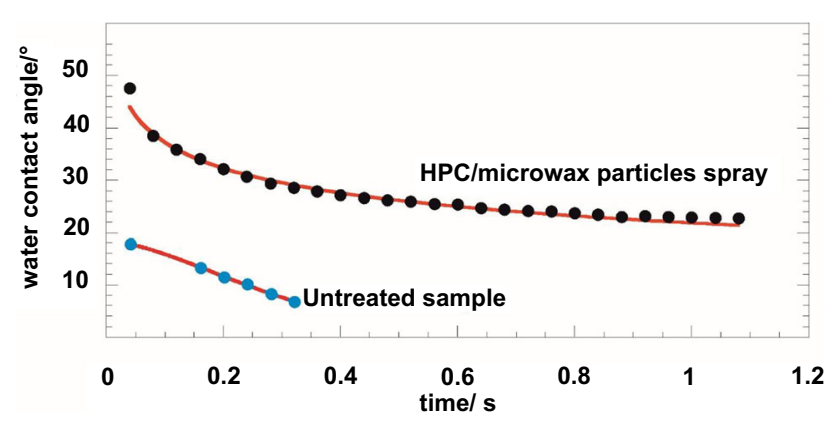

Fig. 6: Water contact angle data on untreated stone and HPC/microwax particles treated stone by spray method.

\section{Colorimetric analysis and wettability}

The investigation of a protective coating in cultural heritage must take into account also the level of aspect alteration due to the presence of the protective film itself. Undoubtedly, this level should be as low as possible. With this in mind, we performed colorimetric analysis on the stone before and after the treatment to highlight the changes in the appearance of the surface. The color parameters in the laboratory scale are reported in Table 1 for all the investigated surfaces. It is noteworthy that pure HPC does not alter the lightness and the red-green parameter of the stone whilst only the yellow-blue value is slightly affected, with a total color difference $(\Delta \mathrm{E})$ that is 1.4. Since a $\Delta \mathrm{E}$ value of 2.3 up to 4 corresponds to just a noticeable difference by human eyes, it is clear that pure HPC $(\Delta \mathrm{E}<2.3)$ has actually no effects by the colorimetric point of view. ${ }^{60,63}$ These findings were expected due to the high transparency in visible light of the polymeric matrix. $^{64}$ As long as the microwax particles are concerned, instead, their presence generates a major alteration of the color parameters as a consequence of the two application methods. In particular, both the lightness and the yellow tone have been altered upon spraying the surface with the HPC/wax microparticles formulation. Indeed, the total color difference reaches a value of 3.3 but still the variation cannot be clearly perceived by human eyes. Moreover, all the colorimetric parameters are more affected by applying the 
coating using a brush. In this latter case, for instance, the $\Delta \mathrm{E}$ values increase up to 6.0. Therefore, the brush application should be considered with particular attention due to the more significant color change it can cause (Table 1). The UV-Vis analysis of the nanocomposite biofilms also gave similar results. (Spectra are reported in Supporting Information.) In particular, the transmittance (T\%) of radiation at $700 \mathrm{~nm}$ is ca. $93 \%$ and $69 \%$ for the pure HPC film and for the wax/HNTs/ HPC nanocomposite. Hence, it is clear that the wax/nanotubes systems also affect the transparency of the protective coating which decreases due to the presence of the microparticles, even before the application on the stone substrate.

Afterwards, water adhesion property on the surface was analyzed by the time-resolved contact angle measurements (see Fig. 6). To do it, we analyzed the profiles of a minimum of three droplets per sample and calculated the average values in order to provide more robust data. The untreated stone showed a very high water affinity with low contact angle (below $20^{\circ}$ ) just after the drop deposition and, then, a fast decrease until the complete droplet adsorption by the porous stone was observed. After the treatment with HPC/wax microparticles, instead, the initial contact angle value was larger than the value of the bare stone. Moreover, despite the difference between the two application methods (i.e. spray or brush), HPC film provided a quick decrease of the contact angle until the full water adsorption was reached (complete curves are reported in Fig. S2).

More interestingly, the nanocomposites containing the wax microparticles have the best performance providing higher initial contact angle values, due to their more hydrophobic character compared with untreated stone, which smoothly decrease as a function of time. In this case, the full adsorption occurs in a wider timeframe, as reported in Fig. 6.

For a quantitative description of the time-resolved water contact angle data $(\vartheta)$, we used an exponential function $^{65}$ :

$\vartheta=\theta_{i} \exp \left(-k \tau^{n}\right)$

where $\left(\theta_{i}\right)$ is the zero-time water contact angle value, $k$ measures the process rate, and $n$ is expected to assume values between 0 and 1 depending on the spreading/ adsorption mechanism. The obtained parameters are reported in Table 2. It should be noted that the nanocomposite layer not only decreases the surface hydrophilicity, represented by the $\theta_{i}$ significant enhancement, but also the process kinetics are altered in agreement with the morphological investigations. For what concerns the $n$ parameter, its variation is referred to as a major contribution of either the spreading $(n=1)$ or the adsorption mechanisms $(n=0)$. It is clear that both the phenomena are strictly interconnected, since the stone surface most likely becomes more hydrophilic upon water adsorption, with a consequent increase of the spreading contribution.

Hence, in order to enlighten these aspects and to provide more precise details, the variation of the droplet volume as a function of time has been focused, by considering the droplet perfectly symmetric (Fig. 7).

It is possible to observe that, yet after $0.3 \mathrm{~s}$, the volume of the water droplet falls to ca. $35 \%$ for the untreated stone, thus meaning that the liquid is being adsorbed by the porous material. Similar trends have been found for the pure HPC coating, applied by either spray or brush, with a high rate of volume decrease as a consequence of water adsorption. In the cases of HPC/ wax microparticles protective layers, instead, the volume reduction shows a smooth decrease over time and

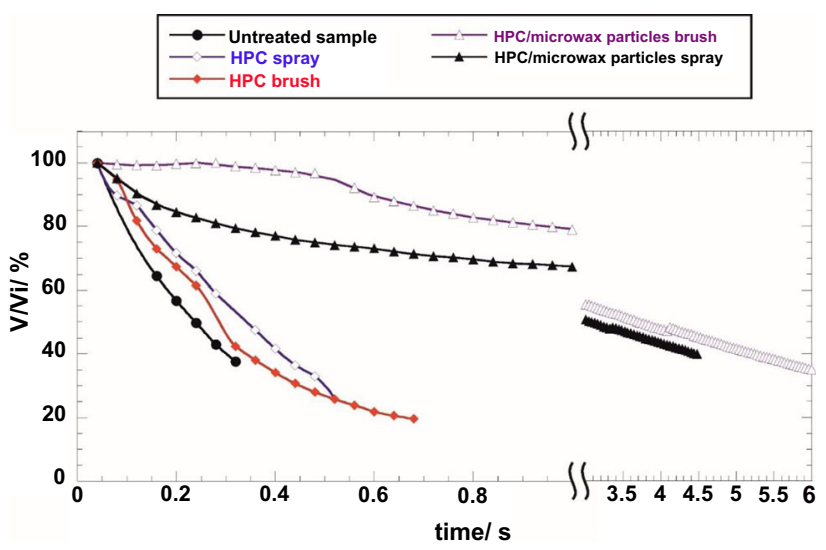

Fig. 7: Variation of the water droplets volume on stone before and after surface treatment as a function of time.

Table 2: Fitting parameters from water contact angle data.

\begin{tabular}{lccc} 
& $\theta j^{\circ}$ & $k / s^{-n}$ & $n$ \\
\hline Untreated sample & $20.3 \pm 0.9$ & $3.2 \pm 0.3$ & $1.0 \pm 0.1$ \\
HPC (spray) & $68 \pm 2$ & $5.3 \pm 0.2$ & $1.0 \pm 0.3$ \\
HPC (brush) & $57 \pm 7$ & $4.6 \pm 0.9$ & $1.0 \pm 0.4$ \\
HPC/microwax particles (spray) & $76 \pm 6$ & $1.2 \pm 0.3$ & $0.18 \pm 0.05$ \\
HPC/microwax particles (brush) & $77 \pm 4$ & $1.41 \pm 0.06$ & $0.214 \pm 0.009$ \\
\hline
\end{tabular}


the droplets can be still observed after many seconds. This is most likely related to the importance of the spreading contribution and to its synergistic effect with the adsorption mechanism. Whilst the droplet spreading on the surface slightly affects the total volume, the adsorption is responsible for an important decrease of the water amount on the surface. Therefore, even if the droplets are slowly being adsorbed by the material, its major tendency is to spread on it after the treatment with the HPC/microwax formulation, regardless of the particular application method.

\section{Conclusions}

We demonstrated that wax microparticles dispersed in a biopolymeric matrix by using halloysite nanotubes can generate new nanocomposite films with perspectives in stone protection. The presence of microwax in the material has a fundamental role in the coating effectiveness as the biopolymeric film alone would not represent a valid protective film. In particular, regardless of the application protocol (i.e., brush or spray), we demonstrated the presence of wax/halloysite microparticles on the sample surfaces of the materials as components of the coating biofilm. Nevertheless, the spray method leads to a more uniform coating which is perfectly adherent to the substrate and, as a consequence, more efficient.

The study of the wettability features showed that the affinity of the stone to water is deeply affected and a more hydrophobic surface is obtained upon treatment with effect on the adsorption and spreading mechanisms of the liquid droplet onto the solid substrate. Moreover, the brush application alters the visual and macroscopic aspect of the surface as the color coordinates clearly indicates, contrarily to the spray method. Therefore, the latter application protocol would be the most suitable not only due to its efficacy but also taking into account the possibility to scale up the process.

Acknowledgments The work was financially supported by Progetto di ricerca e sviluppo "AGM for CuHe" (ARS01_00697) and University of Palermo.

\begin{abstract}
Authors' Contributions MRC contributed to investigation, writing-original draft. BM contributed to optical and scanning electron microscopy images acquisition. LL contributed to writing-review and editing, data curation. GC contributed to conceptualization and validation. SM contributed to funding acquisition and resources. GL contributed to supervision and conceptualization.Funding Open access funding provided by Università degli Studi di Palermo within the CRUI-CARE Agreement. None.
\end{abstract}

Conflict of interest The authors have no conflict of interest.
Open Access This article is licensed under a Creative Commons Attribution 4.0 International License, which permits use, sharing, adaptation, distribution and reproduction in any medium or format, as long as you give appropriate credit to the original author(s) and the source, provide a link to the Creative Commons licence, and indicate if changes were made. The images or other third party material in this article are included in the article's Creative Commons licence, unless indicated otherwise in a credit line to the material. If material is not included in the article's Creative Commons licence and your intended use is not permitted by statutory regulation or exceeds the permitted use, you will need to obtain permission directly from the copyright holder. To view a copy of this licence, visit http://creativecommons.org/licenses/by/4.0/.

\section{References}

1. Cappa, F, Paganoni, I, Carsote, C, et al. "Studies on the Effects of Mixed Light-Thermal Ageing on Parchment by Vibrational Spectroscopy and Micro Hot Table Method." Heritage Sci., 8 15-27. https://doi.org/10.1186/s40494-020-03 53-z (2020)

2. Sbardella, F, Bracciale, MP, Santarelli, ML, Asua, JM, "Waterborne Modified-Silica/Acrylates Hybrid Nanocomposites as Surface Protective Coatings for Stone Monuments." Prog. Org. Coat., 149 105897-105910. https://doi.org/ 10.1016/j.porgcoat.2020.105897 (2020)

3. Curulli, A, Montesperelli, G, Ronca, S, et al. "A Multidisciplinary Approach to the Mortars Characterization from the Town Walls of Gubbio (Perugia, Italy)." J. Therm. Anal. Calorim., 142 1721-1737. https://doi.org/10.1007/s10973-02009937-9 (2020)

4. Cappa, F, Paganoni, I, Carsote, C, et al. "Studies on the Effect of Dry-Heat Ageing on Parchment Deterioration by Vibrational Spectroscopy and Micro Hot Table Method." Polym. Degrad. Stab., 182 109375-109386. https://doi.org/10. 1016/j.polymdegradstab.2020.109375 (2020)

5. Kapridaki, C, Maravelaki-Kalaitzaki, $\mathrm{P}$, " $\mathrm{TiO}_{2}-\mathrm{SiO}_{2}-\mathrm{PDMS}$ Nano-Composite Hydrophobic Coating with Self-Cleaning Properties for Marble Protection." Prog. Org. Coat., 76 400410. https://doi.org/10.1016/j.porgcoat.2012.10.006 (2013)

6. Brugnara, M, Degasperi, E, Volpe, CD, et al. "The Application of the Contact Angle in Monument Protection: New Materials and Methods." Colloids Surf. A Physicochem. Eng. Aspects, 241 299-312. https://doi.org/10.1016/j.colsurfa.2004. 04.035 (2004)

7. Favaro, M, Mendichi, R, Ossola, F, et al. "Evaluation of Polymers for Conservation Treatments of Outdoor Exposed Stone Monuments. Part I: Photo-Oxidative Weathering." Polym. Degrad. Stab., 91 3083-3096. https://doi.org/10.1016/j. polymdegradstab.2006.08.012 (2006)

8. Chang, C-C, Wu, Y-T, Cheng, L-P, "Preparation of HMDSModified Silica/Polyacrylate Hydrophobic Hard Coatings on PMMA Substrates." J. Coat. Technol. Res., 13 999-1007. h ttps://doi.org/10.1007/s11998-016-9820-6 (2016)

9. Wang, M, Ning, Y, Han, W, Zhao, T, “Oligosilazane Cured by Moisture as Fluorine-Free Hydrophobic Coating for Waterproof Polymer-Matrix Composite Materials." J. Coat. Technol. Res., 15 1251-1258. https://doi.org/10.1007/s11998018-0092-1 (2018) 
10. Su, C, "A Simple and Cost-Effective Method for Fabricating Lotus-Effect Composite Coatings." J. Coat. Technol. Res., 9 135-141. https://doi.org/10.1007/s11998-009-9230-0 (2012)

11. Ruffolo, SA, La Russa, MF, "Nanostructured Coatings for Stone Protection: An Overview." Front Mater., 6 1-8. http s://doi.org/10.3389/fmats.2019.00147 (2019)

12. Ates, B, Koytepe, S, Ulu, A, et al. "Chemistry, Structures, and Advanced Applications of Nanocomposites from Biorenewable Resources." Chem. Rev., 120 9304-9362. https://doi. org/10.1021/acs.chemrev.9b00553 (2020)

13. Stetsyshyn, Y, Awsiuk, K, Kusnezh, V, et al. "ShapeControlled Synthesis Of Silver Nanoparticles in Temperature-Responsive Grafted Polymer Brushes for Optical Applications." Appl. Surf. Sci., 463 1124-1133. https://doi. org/10.1016/j.apsusc.2018.09.033 (2019)

14. Bakshi, SR, Balani, K, Laha, T, et al. "The Nanomechanical and Nanoscratch Properties of MWNT-Reinforced Ultrahigh-Molecular-Weight Polyethylene Coatings." JOM, 59 50-53. https://doi.org/10.1007/s11837-007-0089-1 (2007)

15. Bonomi, S, Marongiu, D, Sestu, N, et al. "Novel Physical Vapor Deposition Approach to Hybrid Perovskites: Growth of $\mathrm{MAPbI}_{3}$ Thin Films by RF-Magnetron Sputtering." Sci. Rep., 8 1-8. https://doi.org/10.1038/s41598-018-33760-w (2018)

16. Catauro, M, Dal Poggetto, G, Sgarlata, C, et al. "Thermal and Microbiological Performance of Metakaolin-Based Geopolymers Cement with Waste Glass." Appl. Clay Sci., 197 105763. https://doi.org/10.1016/j.clay.2020.105763 (2020)

17. Fermo, P, Cappelletti, G, Cozzi, N, et al. "Hydrophobizing Coatings for Cultural Heritage: A Detailed Study of Resin/ Stone Surface Interaction." Appl. Phys. A, 116 341-348. h ttps://doi.org/10.1007/s00339-013-8127-z (2014)

18. Catauro, M, Barrino, F, Dal Poggetto, G, et al. "Structure, Drug Absorption, Bioactive and Antibacterial Properties of Sol-Gel SiO $2 / \mathrm{ZrO}_{2}$ Materials." Ceram. Int., 46 29459-29465. https://doi.org/10.1016/j.ceramint.2020.03.167 (2020)

19. Janiszewska, N, Raczkowska, J, Budkowski, A, et al. "Dewetting of Polymer Films Controlled by Protein Adsorption." Langmuir, 36 11817-11828. https://doi.org/10.1021/acs. langmuir.0c01718 (2020)

20. Rebitski, EP, Souza, GP, Santana, SAA, et al. "Bionanocomposites Based on Cationic and Anionic Layered Clays as Controlled Release Devices of Amoxicillin." Appl. Clay Sci., 173 35-45. https://doi.org/10.1016/j.clay.2019.02.024 (2019)

21. Blanco, I, Bottino, FA, Ognibene, G, Cicala, G, “A Novel Polystyrene Nanocomposite with Fully Phenyl POSSs Functionalized." Macromol. Symp., 389 1900070-1900074. http s://doi.org/10.1002/masy.201900070 (2020)

22. Andreotti, S, Franzoni, E, Degli Esposti, M, Fabbri, P, "Poly(hydroxyalkanoate)s-Based Hydrophobic Coatings for the Protection of Stone in Cultural Heritage." Materials, 11 165-191. https://doi.org/10.3390/ma11010165 (2018)

23. Cavallaro, G, Milioto, S, Nigamatzyanova, L, et al. "Pickering Emulsion Gels Based on Halloysite Nanotubes and Ionic Biopolymers: Properties and Cleaning Action on Marble Surface." ACS Appl. Nano Mater., 2 3169-3176. https://doi. org/10.1021/acsanm.9b00487 (2019)

24. Carretti, E, Fratini, E, Berti, D, et al. "Nanoscience for Art Conservation: Oil-in-Water Microemulsions Embedded in a Polymeric Network for the Cleaning of Works of Art." Angew. Chem. Int. Ed., 48 8966-8969. https://doi.org/10.100 2/anie.200904244 (2009)

25. Sansonetti, A, Bertasa, M, Canevali, C, et al. "A Review in Using Agar Gels for Cleaning Art Surfaces.” J. Cult. Herit.,
44 285-296. https://doi.org/10.1016/j.culher.2020.01.008 (2020)

26. Bonelli, N, Poggi, G, Chelazzi, D, et al. "Poly(vinyl alcohol)/ poly(vinyl pyrrolidone) Hydrogels for the Cleaning of Art." J. Colloid Interf. Sci., 536 339-348. https://doi.org/10.1016/j.jc is.2018.10.025 (2019)

27. Mastrangelo, R, Montis, C, Bonelli, N, et al. "Surface Cleaning of Artworks: Structure and Dynamics of Nanostructured Fluids Confined in Polymeric Hydrogel Networks." Phys. Chem. Chem. Phys., 19 23762-23772. h ttps://doi.org/10.1039/C7CP02662E (2017)

28. Ocak, Y, Sofuoglu, A, Tihminlioglu, F, Böke, H, "Sustainable Bio-nano Composite Coatings for the Protection of Marble Surfaces." J. Cult. Herit., 16 299-306. https://doi.org/ 10.1016/j.culher.2014.07.004 (2015)

29. Pedna, A, Pinho, L, Frediani, P, Mosquera, MJ, "Obtaining $\mathrm{SiO}_{2}$-Fluorinated PLA Bionanocomposites with Application as Reversible and Highly-Hydrophobic Coatings of Buildings." Prog. Org. Coat., 90 91-100. https://doi.org/10.1016/j. porgcoat.2015.09.024 (2016)

30. Poggi, G, Toccafondi, N, Melita, LN, et al. "Calcium Hydroxide Nanoparticles for the Conservation of Cultural Heritage: New Formulations for the Deacidification of Cellulose-based Artifacts." Appl. Phys. A, 114 685-693. h ttps://doi.org/10.1007/s00339-013-8172-7 (2014)

31. Liu, B, Wang, L, Zhang, Y, et al. "Monomer Self-Deposition Synthesis of N-Doped Mesoporous Carbon Tubes using Halloysite as Template for Supercapacitors." J. Mater. Sci., 56 3312-3324. https://doi.org/10.1007/s10853-020-05414-8 (2021)

32. Bischoff, E, Simon, DA, Liberman, SA, Mauler, RS, “Influence of the Dispersing Agents to Obtain Polymer-Clay Nanocomposites Processed in Two-Steps using Thermokinetic Mixer." J. Mater. Sci., 55 6537-6550. https://doi.org/10. 1007/s10853-020-04443-7 (2020)

33. Cordenonsi, LM, Faccendini, A, Catanzaro, M, et al. "The Role of Chitosan as Coating Material for Nanostructured Lipid Carriers for Skin Delivery of Fucoxanthin." Int. J. Pharm., 567 118487-118497. https://doi.org/10.1016/j.ijphar m.2019.118487 (2019)

34. Zhao, Y, Kong, W, Jin, Z, et al. "Storing Solar Energy within Ag-Paraffin@Halloysite Microspheres as a Novel Self-heating Catalyst." Appl. Energy, 222 180-188. https://doi.org/10. 1016/j.apenergy.2018.04.013 (2018)

35. Barreca, S, Bruno, M, Oddo, L, Orecchio, S, "Preliminary Study on Analysis and Removal of Wax from a Carrara Marble Statue.' Nat. Prod. Res., 33 947-955. https://doi.org/ 10.1080/14786419.2015.1113411 (2019)

36. Bertolino, V, Cavallaro, G, Milioto, S, Lazzara, G, "Polysaccharides/Halloysite Nanotubes for Smart Bionanocomposite Materials." Carbohydr. Polym., 245 116502-116513. https://d oi.org/10.1016/j.carbpol.2020.116502 (2020)

37. Yang, X, Zhang, Y, Zheng, D, et al. "Nano-biocomposite Films Fabricated from Cellulose Fibers and Halloysite Nanotubes." Appl. Clay Sci., 190 105565-105574. https://d oi.org/10.1016/j.clay.2020.105565 (2020)

38. Okahashi, K, Takeuchi, M, Zhou, Y, et al. "NanocelluloseContaining Cellulose ether Composite Films Prepared from Aqueous Mixtures by Casting and Drying Method." Cellulose, 28 6373-6387. https://doi.org/10.1007/s10570-021-03897 $-5(2021)$

39. Panchal, A, Swientoniewski, LT, Omarova, M, et al. "Bacterial Proliferation on Clay Nanotube Pickering Emulsions for Oil Spill Bioremediation."' Colloids Surf. B Biointerf., 164 27-33. https://doi.org/10.1016/j.colsurfb.2018.01.021 (2018) 
40. Owoseni, O, Nyankson, E, Zhang, Y, et al. "Release of Surfactant Cargo from Interfacially-Active Halloysite Clay Nanotubes for Oil Spill Remediation." Langmuir, 30 1353313541. https://doi.org/10.1021/la503687b (2014)

41. Lisuzzo, L, Cavallaro, G, Parisi, F, et al. "Colloidal Stability of Halloysite Clay Nanotubes.” Ceram. Int., 45 2858-2865. h ttps://doi.org/10.1016/j.ceramint.2018.07.289 (2019)

42. von Klitzing, R, Stehl, D, Pogrzeba, T, et al. "Halloysites Stabilized Emulsions for Hydroformylation of Long Chain Olefins." Adv. Mater. Interf., 4 (1) 1600435. https://doi.org/ 10.1002/admi.201600435 (2017)

43. Sadjadi, S, Akbari, M, Monflier, E, et al. "Pd Nanoparticles Immobilized on Halloysite Decorated with a Cyclodextrin Modified Melamine-Based Polymer: A Promising Heterogeneous Catalyst for Hydrogenation of Nitroarenes." New J. Chem., 42 15733-15742. https://doi.org/10.1039/C8NJ03014F (2018)

44. Pasbakhsh, P, Churchman, GJ, Keeling, JL, "Characterisation of Properties of Various Halloysites Relevant to Their Use as Nanotubes and Microfibre Fillers." Appl. Clay Sci., 74 47-57. https://doi.org/10.1016/j.clay.2012.06.014 (2013)

45. Lisuzzo, L, Cavallaro, G, Pasbakhsh, P, et al. "Why Does Vacuum Drive to the Loading of Halloysite Nanotubes? The Key Role of Water Confinement." J. Colloid Interf. Sci., 547 361-369. https://doi.org/10.1016/j.jcis.2019.04.012 (2019)

46. Zhang, Y, Bai, L, Cheng, C, et al. "A Novel Surface Modification Method Upon Halloysite Nanotubes: A Desirable Cross-Linking Agent to Construct Hydrogels." Appl. Clay Sci., 182 105259-105267. https://doi.org/10.1016/j.clay.2 019.105259 (2019)

47. Fakhrullina, GI, Akhatova, FS, Lvov, YM, Fakhrullin, RF, "Toxicity of Halloysite Clay Nanotubes In Vivo: A Caenorhabditis elegans Study." Environ. Sci. Nano, 2 5459. https://doi.org/10.1039/C4EN00135D (2015)

48. Kryuchkova, M, Danilushkina, A, Lvov, Y, Fakhrullin, R, "Evaluation of Toxicity of Nanoclays and Graphene Oxide In Vivo: A Paramecium caudatum Study." Environ. Sci. Nano, 3 442-452. https://doi.org/10.1039/C5EN00201J (2016)

49. Liu, M, Jia, Z, Liu, F, et al. "Tailoring the Wettability of Polypropylene Surfaces with Halloysite Nanotubes." $J$. Colloid Interf. Sci., 350 186-193. https://doi.org/10.1016/j.jc is.2010.06.047 (2010)

50. Lisuzzo, L, Wicklein, B, Dico, GL, et al. "Functional Biohybrid Materials Based on Halloysite, Sepiolite and Cellulose Nanofibers for Health Applications." Dalton Trans., 49 3830-3840. https://doi.org/10.1039/C9DT03804C (2020)

51. De Silva, RT, Pasbakhsh, P, Goh, KL, et al. "PhysicoChemical Characterisation of Chitosan/Halloysite Composite Membranes." Polym. Test., 32 265-271. https://doi.org/10. 1016/j.polymertesting.2012.11.006 (2013)

52. Cavallaro, G, Milioto, S, Lazzara, G, "Halloysite Nanotubes: Interfacial Properties and Applications in Cultural Heritage." Langmuir, 36 3677-3689. https://doi.org/10.1021/acs.la ngmuir.0c00573 (2020)

53. Cavallaro, G, Milioto, S, Parisi, F, Lazzara, G, "Halloysite Nanotubes Loaded with Calcium Hydroxide: Alkaline Fillers for the Deacidification of Waterlogged Archeological
Woods." ACS Appl. Mater. Interf., 10 27355-27364. https:// doi.org/10.1021/acsami.8b09416 (2018)

54. Makaremi, M, Pasbakhsh, P, Cavallaro, G, et al. "Effect of Morphology and Size of Halloysite Nanotubes on Functional Pectin Bionanocomposites for Food Packaging Applications." ACS Appl. Mater. Interf., 9 17476-17488. https://doi. org/10.1021/acsami.7b04297 (2017)

55. Bugatti, V, Vertuccio, L, Zara, S, et al. "Green Pesticides Based on Cinnamate Anion Incorporated in Layered Double Hydroxides and Dispersed in Pectin Matrix." Carbohydr. Polym., 209 356-362. https://doi.org/10.1016/j.carbpol.2019.0 1.033 (2019)

56. Lisuzzo, L, Cavallaro, G, Milioto, S, Lazzara, G, “Layered Composite Based on Halloysite and Natural Polymers: A Carrier for the $\mathrm{pH}$ Controlled Release of Drugs." New J. Chem., 43 10887-10893. https://doi.org/10.1039/C9NJ02565K (2019)

57. Liu, F, Bai, L, Zhang, H, et al. "Smart $\mathrm{H}_{2} \mathrm{O}_{2}$-Responsive Drug Delivery System Made by Halloysite Nanotubes and Carbohydrate Polymers." ACS Appl. Mater. Interf., 931626 31633. https://doi.org/10.1021/acsami.7b10867 (2017)

58. Zhao, Y, Abdullayev, E, Vasiliev, A, Lvov, Y, "Halloysite Nanotubule Clay for Efficient Water Purification." J. Colloid Interf. Sci., 406 121-129. https://doi.org/10.1016/j.jcis.2013.05. $072(2013)$

59. Zhu, Z, Ma, C, Yu, K, et al. "Fabrication of $\mathrm{CoFe}_{2} \mathrm{O}_{4}$ Modified and HNTs-Supported g- $\mathrm{C}_{3} \mathrm{~N}_{4}$ Heterojunction Photocatalysts for Enhancing MBT Degradation Activity Under Visible Light.' J. Mater. Sci., 55 4358-4371. https://doi.org/ 10.1007/s10853-019-04170-8 (2020)

60. Sharma, G, Bala, R, Bala, R, Digital Color Imaging Handbook. CRC Press, Boca Raton (2017)

61. Xuan, S, Zhang, Y, Zhou, Y, et al. "Magnetic Plasticine ${ }^{\mathrm{TM}}$ : A Versatile Magnetorheological Material." J. Mater. Chem., 22 13395-13400. https://doi.org/10.1039/C2JM32375C (2012)

62. Lisuzzo, L, Caruso, MR, Cavallaro, G, et al. "Hydroxypropyl Cellulose Films Filled with Halloysite Nanotubes/Wax Hybrid Microspheres." Ind. Eng. Chem. Res., 60 16561665. https://doi.org/10.1021/acs.iecr.0c05148 (2021)

63. Meng, B, Mueller, U, Garcia, O, Malaga, K, "Performance of a New Anti-Graffiti Agent Used for Immovable Cultural Heritage Objects." Int. J. Arch. Herit., 8 820-834. https://doi. org/10.1080/15583058.2012.747116 (2014)

64. Cavallaro, G, Donato, DI, Lazzara, G, Milioto, S, "Films of Halloysite Nanotubes Sandwiched Between Two Layers of Biopolymer: From the Morphology to the Dielectric, Thermal, Transparency, and Wettability Properties." J. Phys. Chem. C, 115 20491-20498. https://doi.org/10.1021/jp207261r (2011)

65. Farris, S, Introzzi, L, Biagioni, P, et al. "Wetting of Biopolymer Coatings: Contact Angle Kinetics and Image Analysis Investigation." Langmuir, 27 7563-7574. https://doi. org/10.1021/la2017006 (2011)

Publisher's Note Springer Nature remains neutral with regard to jurisdictional claims in published maps and institutional affiliations. 